\title{
Evaluating the performance of two surface layer schemes for the momentum and heat exchange processes during severe haze pollution in Jing-Jin-Ji in eastern China
}

\author{
Yue Peng ${ }^{1,2}$, Hong Wang ${ }^{1,2}$, Yubin $\mathrm{Li}^{3}$, Changwei Liu ${ }^{3}$, Tianliang Zhao ${ }^{2}$, Xiaoye Zhang ${ }^{1}$, Zhiqiu Gao ${ }^{3,4}$, Tong Jiang ${ }^{5}$, \\ Huizheng Che ${ }^{1}$, and Meng Zhang ${ }^{6}$ \\ ${ }^{1}$ State Key Laboratory of Severe Weather/Institute of Atmospheric Composition, \\ Chinese Academy of Meteorological Sciences (CMAS), Beijing 100081, China \\ ${ }^{2}$ Collaborative Innovation Center on Forecast and Evaluation of Meteorological Disasters/Key Laboratory for \\ Aerosol-Cloud-Precipitation of China Meteorological Administration, Nanjing University of Information Science and \\ Technology, Nanjing 210044, China \\ ${ }^{3}$ Key Laboratory of Meteorological Disaster of Ministry of Education/Collaborative Innovation Center on Forecast and \\ Evaluation of Meteorological Disasters, School of Atmospheric Physics, Nanjing University of Information Science and \\ Technology, Nanjing 210044, China \\ ${ }^{4}$ State Key Laboratory of Atmospheric Boundary Layer Physics and Atmospheric Chemistry, Institute of Atmospheric \\ Physics, Chinese Academy of Sciences, Beijing 100029, China \\ ${ }^{5}$ National Climate Center, China Meteorological Administration, Beijing 100081, China \\ ${ }^{6}$ Beijing Meteorological Service, Beijing 100089, China \\ Correspondence: Hong Wang (wangh@cma.gov.cn)
}

Received: 8 March 2018 - Discussion started: 25 April 2018

Revised: 14 November 2018 - Accepted: 27 November 2018 - Published: 10 December 2018

\begin{abstract}
The turbulent flux parameterization schemes in the surface layer are crucial for air pollution modeling. There have been some deficiencies in the prediction of air pollutants by atmosphere chemical models, which is closely related to the uncertainties of the momentum and sensible heat fluxes calculated in the surface layer. The differences between two surface layer schemes (Li and MM5 schemes) were discussed, and the performances of two schemes were mainly evaluated based on the observed momentum and sensible heat fluxes during a heavy haze episode in Jing-Jin-Ji in eastern China. The results showed that the aerodynamic roughness length $z_{0 m}$ and the thermal roughness length $z_{0 h}$ played major roles in the flux calculation. Compared with the Li scheme, ignoring the difference between $z_{0 m}$ and $z_{0 h}$ in the MM5 scheme induced a great error in the calculation of the sensible heat flux (e.g., the error was $54 \%$ at Gucheng station). Besides the roughness length, the algorithm for the surface turbulent flux as well as the roughness sublayer also resulted in certain errors in the MM5 scheme. In addition, magnitudes of $z_{0 m}$ and $z_{0 h}$ have significant influence on the
\end{abstract}

two schemes. The large $z_{0 m}$ and $z_{0 m} / z_{0 h}$ in megacities with a rough surface (e.g., Beijing) resulted in much larger differences of momentum and sensible heat fluxes between $\mathrm{Li}$ and MM5, compared with the small $z_{0 m}$ and $z_{0 m} / z_{0 h}$ in suburban areas with a smooth surface (e.g., Gucheng). The Li scheme could better characterize the evolution of atmospheric stratification than the MM5 scheme in general, especially for the transition stage from unstable to stable atmospheric stratification, corresponding to the $\mathrm{PM}_{2.5}$ accumulation. The biases of momentum and sensible heat fluxes from $\mathrm{Li}$ were lower, about $38 \%$ and $43 \%$, respectively, than those from MM5 during this stage. This study indicates the superiority of the Li scheme in describing regional atmospheric stratification and an improved possibility of severe haze prediction in Jing-Jin-Ji in eastern China by coupling it into atmosphere chemical models. 


\section{Introduction}

Adequate air quality modeling relies on the accurate simulation of meteorological conditions, especially in the planetary boundary layer (PBL) (Hu et al., 2010; Cheng et al., 2012; Xie et al., 2012). The PBL is tightly coupled with the earth's surface through turbulent exchange processes. As the bottom layer of the PBL, the surface layer (SL) reflects the surface state by calculating momentum, heat, water vapor, and other fluxes, and influences the atmospheric structure through a turbulent transport process. Many studies have illustrated the important roles of meteorological factors in the SL during air pollution formation. It has been demonstrated that weak wind speed, high relative humidity (RH), and strong temperature inversion are favorable for the concentration of haze (Zhang et al., 2014; Yang et al., 2015; Liu et al., 2017; Zhong et al., 2018). Strong stable stratification and weak turbulence are mainly responsible for many haze events. The relationship between the flux and the atmospheric profile in the atmospheric surface layer is a critical factor for air pollution diffusion, especially under stable stratification conditions ( $\mathrm{Li}$ et al., 2017). However, there are still some uncertainties in the study of the stable boundary layer due to the poor description of surface turbulent motion. The simulation study on a severe haze in eastern China by the Weather Research and Forecasting with Chemistry (WRF-Chem) model concluded that current PBL schemes have a weak ability to distinguish between haze days under stable conditions and clean days under unstable conditions (T. Li et al., 2016). Another study (Vautard et al., 2012) of mesoscale meteorological models also pointed out there was a systematic overestimation of near-surface wind speed in the stable boundary layer which should contribute to the underestimation of surface concentrations of primary pollution. In addition, atmospheric conditions in both the PBL and upper layers are highly dependent on turbulent fluxes which are computed in the SL (Ban et al., 2010). Flux parameterization in the SL plays an important role in studies of the hydrological cycle and weather prediction (Yang et al., 2001; Li, 2014). An adequate SL scheme is crucial in providing an accurate atmospheric evolution by numerical models (Jiménez et al., 2012) and hence it may introduce significant impacts on air pollution simulation.

The bulk aerodynamic formulation based on MoninObukhov similarity theory (hereinafter MOST; Monin and Obukhov, 1954) is usually employed to calculate surface fluxes in numerical models. Turbulent fluxes are parameterized by wind, temperature, humidity in the lowest layer in the model, and temperature and humidity at the surface. Many international scholars verified MOST using field experiments and then proposed the universal functions, the most commonly used of which is the Businger-Dyer (BD) equation (Businger, 1966; Dyer, 1967). With the development of observation technology, the coefficients in the BD equation have been further modified (Paulson, 1970; Webb, 1970; Businger et al., 1971; Dyer, 1974; Högström, 1996).
In addition to the $\mathrm{BD}$ equation, some other schemes have been put forward and they performed better, especially for strongly stable stratification (Holtslag and De Bruin, 1988; Beljaars and Holtslag, 1991; Cheng and Brutsaert, 2005). The schemes can be divided into two types according to the computing characteristics. One type is called an iterative algorithm (Paulson, 1970; Businger et al., 1971; Dyer, 1974; Högström, 1996; Beljaars and Holtslag, 1991), and it keeps MOST completely with less approximation so that the results can be more precise. However, many more steps are necessary for it to converge, and hence the CPU time is longer, which reduces the computational efficiency of modeling (Louis, 1979; Li et al., 2014). The other one is called a non-iterative algorithm (Louis et al., 1982; Launiainen, 1995; Wang et al., 2002; Wouters et al., 2012). There is no requirement for loop iteration in the calculation due to the approximate treatment. This algorithm is much simpler and less CPU-time-consuming, but the results are based on the loss of the calculation accuracy.

A new non-iterative scheme proposed by $\mathrm{Li}$ et al. (2014, 2015; Li hereinafter) speeds up effectively with a higher accuracy compared with classic iterative computation. It is remarkable that this new scheme has just been theoretically evaluated and it has never been applied in any models. Haze pollution has occurred frequently in recent years in eastern China. The concentration of $\mathrm{PM}_{2.5}$ may reach up to $1000 \mu \mathrm{g} \mathrm{m}^{-3}$ in the Beijing-Tianjin-Hebei (Jing-Jin-Ji) region in winter (Wang et al., 2014), while it is generally underestimated by current air quality models (Zhang et al., 2015; T. Li et al., 2016; Liu et al., 2017). The Li and another classic SL scheme (Zhang and Anthes, 1982; MM5 hereinafter) were compared in detail in this study. The observed momentum and sensible heat flux data covering one complete haze process at Gucheng station were used to evaluate the two schemes, focusing on the transition stage from unstable to stable atmospheric stratification, corresponding to the $\mathrm{PM}_{2.5}$ accumulation. The evaluation is in view of both local and regional scales. This study may provide the prerequisite for coupling the Li scheme into atmosphere chemical models in the future.

\section{Theory}

The definitions of momentum and sensible heat fluxes as well as the detailed algorithms of the Li and MM5 schemes are introduced in this section.

\subsection{Introduction of momentum and sensible heat fluxes}

The turbulent fluxes from the ground surface are defined as follows:

$$
\begin{aligned}
& \tau=\rho u_{*}^{2}, \\
& H=-\rho c_{p} u_{*} \theta_{*},
\end{aligned}
$$


where $\tau$ is the momentum flux, $H$ is the sensible heat flux, $\rho$ is the air density, $c_{p}$ is the specific heat capacity at constant pressure; $u_{*}$ and $\theta_{*}$ are the friction velocity and the temperature scale, respectively, and they represent the intensity of the vertical turbulent flux transport and are approximately independent of height in the SL.

Both the Li and MM5 schemes are based on bulk flux parameterization. As an important dimensionless parameter related to the stability, the bulk Richardson number $R i_{\mathrm{B}}$ is defined as

$R i_{\mathrm{B}}=\frac{g z\left(\theta-\theta_{\mathrm{g}}\right)}{\theta u^{2}}$,

where $g$ is the acceleration of gravity, $z$ is the reference height which is the lowest level in models, $\theta$ is the mean potential temperature at height $z, \theta_{g}$ is the surface radiometric potential temperature, and $u$ is the mean wind speed at height $z$. Thus, $R i_{\mathrm{B}}$ can be computed through meteorological variables from at least two levels.

\subsection{The Li scheme}

This new scheme employs a non-iterative algorithm to compute the surface fluxes. Its basic idea is to parameterize the stability parameter $\zeta$ directly with $R i_{\mathrm{B}}$ and roughness lengths $\left(z_{0 m}\right.$ and $\left.z_{0 h}\right)$. Specifically, bulk transfer coefficients of the momentum and sensible heat fluxes $\left(C_{\mathrm{M}}\right.$ and $\left.C_{\mathrm{H}}\right)$ are expressed as

$$
\begin{aligned}
C_{\mathrm{M}} & =\frac{u_{*}^{2}}{u^{2}}=\frac{\tau}{\rho u^{2}}, \\
C_{\mathrm{H}} & =\frac{u_{*} \theta_{*}}{u\left(\theta-\theta_{g}\right)}=-\frac{H}{\rho c_{p} u\left(\theta-\theta_{g}\right)} .
\end{aligned}
$$

Based on MOST and considering the roughness sublayer (RSL) effect at the same time, the relationships between the bulk transfer coefficients and the profile functions corresponding to wind and potential temperature are usually expressed as

$$
\begin{aligned}
C_{\mathrm{M}}= & \frac{k^{2}}{\left[\ln \frac{z}{z_{0 m}}-\psi_{\mathrm{M}}\left(\frac{z}{L}\right)+\psi_{\mathrm{M}}\left(\frac{z_{0 m}}{L}\right)+\psi_{\mathrm{M}}^{*}\left(\frac{z}{L}, \frac{z}{z_{*}}\right)\right]^{2}}, \\
C_{\mathrm{H}}= & \frac{k^{2}}{R\left[\ln \frac{z}{z_{0 m}}-\psi_{\mathrm{M}}\left(\frac{z}{L}\right)+\psi_{\mathrm{M}}\left(\frac{z_{0 m}}{L}\right)+\psi_{\mathrm{M}}^{*}\left(\frac{z}{L}, \frac{z}{z_{*}}\right)\right]}, \\
& {\left[\ln \frac{z}{z_{0 h}}-\psi_{\mathrm{H}}\left(\frac{z}{L}\right)+\psi_{\mathrm{H}}\left(\frac{z_{0 h}}{L}\right)+\psi_{\mathrm{H}}^{*}\left(\frac{z}{L}, \frac{z}{z_{*}}\right)\right] }
\end{aligned}
$$

where $k$ is the von Kármán constant, which is 0.4 in both schemes; $R$ is the Prandtl number, which is 1.0 in the two schemes; $z_{0 m}$ and $z_{0 h}$ are the aerodynamic roughness length and the thermal roughness length, respectively; $\psi_{\mathrm{M}}$ and $\psi_{\mathrm{H}}$ are the integrated stability functions for momentum and sensible heat, respectively, which are also called universal functions. $L$ is the Obukhov length $\left(\zeta=\frac{z}{L}\right), \psi_{\mathrm{M}}^{*}$ and $\psi_{\mathrm{H}}^{*}$ are the correction functions accounting for the RSL effect, and $z_{*}$ is the RSL height. It is clear to see that the calculation of the momentum and sensible heat fluxes requires $C_{\mathrm{M}}$ and $C_{\mathrm{H}}$ (or $u_{*}$ and $\theta_{*}$ ), and there are three key points to consider in obtaining them:

1. $z_{0 m}$ and $z_{0 h}$ are two key parameters in the bulk transfer equations. Their definitions and influences will be discussed in Sect. 4.1. Note that both $z_{0 m}$ and $z_{0 h}$ are taken into account by the $\mathrm{Li}$ scheme. In other words, the $\mathrm{Li}$ scheme distinguishes the two principal surface parameters effectively as they generate from different mechanisms.

2. The determination of $\zeta$ is the most crucial problem in the Li scheme. In fact, this new scheme consists of two parts. The first part is proposed for atmospheric stable stratification conditions ( $\mathrm{Li}$ et al., 2014), and the second part then extends the scheme to unstable conditions (Li et al., 2015). For stable conditions, the calculation procedure for a given group of $R i_{\mathrm{B}}, z_{0 m}$, and $z_{0 h}$ is as follows: (1) find the region according to $z_{0 \mathrm{~m}}$ and $z_{0 h}$, (2) find the section according to the region and $R i_{\mathrm{B}}$ with Eq. (5) and given coefficients, and (3) calculate $\zeta$ using Eq. (6) and the given coefficients.

$$
\begin{aligned}
& R i_{\mathrm{Bcp}}=\sum C_{m n}\left(\log L_{0 M}\right)^{m}\left(L_{0 H}-L_{0 M}\right)^{n}, \\
& \zeta=R i_{\mathrm{B}} \sum C_{i j k} R i_{\mathrm{B}}^{i} L_{0 M}^{j}\left(L_{0 H}-L_{0 M}\right)^{k},
\end{aligned}
$$

where $C_{m n}$ and $C_{i j k}$ are the coefficients listed in tables in Li et al. (2014). $L_{0 M}=\ln \frac{z}{z_{0 m}}, L_{0 H}=\ln \frac{z}{z_{0 h}} \cdot m, n=$ $0,1,2$, and $m+n \leq 3 ; i, j, k=0,1,2,3$, and $i+j+k \leq$ 4. Similarly, for unstable conditions, eight regions are divided according to the method from $\mathrm{Li}$ et al. (2015). For each of the regions, $\zeta$ is carried out as follows:

$\zeta=R i_{\mathrm{B}} \frac{L_{0 M}^{2}}{L_{0 H}} \sum C_{i j k}\left(\frac{-R i_{\mathrm{B}}}{1-R i_{\mathrm{B}}}\right)^{i} L_{0 M}^{-j} \mathrm{~L}_{0 H}^{-k}$,

where $C_{i j k}$ is listed in Y. Li et al. (2016), and $i=0,1$; $j, k=0,1,2,3 ; i+j+k \leq 4$.

3. The universal function is also a key factor in flux calculation. The form of universal function here is adopted from Cheng and Brutsaert (2005) under stable conditions (Eq. 8a, b) and it is adopted from Paulson (1970) under unstable conditions (Eq. 9a, b):

$$
\begin{aligned}
& \psi_{\mathrm{M}}(\zeta)=-a \ln \left[\zeta+\left(1+\zeta^{b}\right)^{\frac{1}{b}}\right], \zeta>0 \text { (stable), } \\
& \psi_{\mathrm{H}}(\zeta)=-c \ln \left[\zeta+\left(1+\zeta^{d}\right)^{\frac{1}{d}}\right], \zeta>0 \text { (stable), } \\
& \psi_{\mathrm{M}}(\zeta)=2 \ln \frac{1+x}{2}+\ln \frac{1+x^{2}}{2}-2 \arctan (x)+\frac{\pi}{2},
\end{aligned}
$$


$\zeta<0$ (unstable)

$\psi_{\mathrm{H}}(\zeta)=2 \ln \frac{1+y}{2}, \zeta<0$ (unstable),

where $\quad a=6.1, \quad b=2.5, \quad c=5.3, \quad d=1.1$, $x=(1-16 \zeta)^{1 / 4}, y=(1-16 \zeta)^{1 / 2}$.

In addition, the RSL effect is taken into account in the $\mathrm{Li}$ scheme. The definition and influence of the RSL will also be discussed in Sect. 4.1. De Ridder (2010) proposed the expression of $\psi_{\mathrm{M}}^{*}$ and $\psi_{\mathrm{H}}^{*}$ :

$\psi_{\mathrm{M}}^{*}\left(\zeta, \frac{z}{z_{*}}\right)=\phi_{\mathrm{M}}\left[\left(1+\frac{v}{\mu_{\mathrm{M} z / z_{*}}}\right) \zeta\right]$

$\frac{1}{\lambda} \ln \left(1+\frac{\lambda}{\mu_{\mathrm{M}} z / z_{*}}\right) e^{-\mu_{\mathrm{M}} z / z_{*}}$

$\psi_{\mathrm{H}}^{*}\left(\zeta, \frac{z}{z_{*}}\right)=\phi_{\mathrm{H}}\left[\left(1+\frac{v}{\mu_{\mathrm{H}} z / z_{*}}\right) \zeta\right]$

$\frac{1}{\lambda} \ln \left(1+\frac{\lambda}{\mu_{\mathrm{H} z / z_{*}}}\right) e^{-\mu_{\mathrm{H}} z / z_{*}}$,

where $v=0.5, \mu_{\mathrm{M}}=2.59, \mu_{\mathrm{H}}=0.95, z_{*}=16.7 z_{0 m}, \lambda=$ 1.5; $\phi_{\mathrm{M}}$ and $\phi_{\mathrm{H}}$ are universal functions before integration. Here, set $\chi_{\mathrm{M}}=1+\frac{v}{\mu_{\mathrm{M}} z / z_{*}}, \chi_{\mathrm{H}}=1+\frac{v}{\mu_{\mathrm{H}} z / z_{*}}$ :

$\phi_{\mathrm{M}}\left(\chi_{\mathrm{M}} \zeta\right)=1+a \frac{\chi_{\mathrm{M}} \zeta+\left(\chi_{\mathrm{M}} \zeta\right)^{b}\left[1+\left(\chi_{\mathrm{M}} \zeta\right)^{b}\right]^{\frac{1-b}{b}}}{\chi_{\mathrm{M}} \zeta+\left[1+\left(\chi_{\mathrm{M}} \zeta\right)^{b}\right]^{\frac{1}{b}}}$,

$\zeta>0($ stable $)$

$\phi_{\mathrm{H}}\left(\chi_{\mathrm{H}} \zeta\right)=1+c \frac{\chi_{\mathrm{H}} \zeta+\left(\chi_{\mathrm{H}} \zeta\right)^{d}\left[1+\left(\chi_{\mathrm{H}} \zeta\right)^{d}\right]^{\frac{1-d}{d}}}{\chi_{\mathrm{H}} \zeta+\left[1+\left(\chi_{\mathrm{H}} \zeta\right)^{d}\right]^{\frac{1}{d}}}$

$\zeta>0$ (stable)

$\phi_{\mathrm{M}}\left(\chi_{\mathrm{M}} \zeta\right)=\left(1-16 \chi_{\mathrm{M}} \zeta\right)^{-1 / 4}, \zeta<0$ (unstable),

$\phi_{\mathrm{H}}\left(\chi_{\mathrm{H}} \zeta\right)=\left(1-16 \chi_{\mathrm{H}} \zeta\right)^{-1 / 2}, \zeta<0$ (unstable).

\subsection{The MM5 scheme}

The MM5 scheme is a classic one which is widely applied in modeling investigations (Hu et al., 2010; Wang et al., 2015a, b; Tymvios et al., 2017). This scheme does not distinguish $z_{0 h}$ from $z_{0 m}$; thus the roughness length here is expressed as $z_{0}$. For unstable conditions, the function forms are given by Eq. (16a, b) following Paulson (1970), and for stable conditions, the atmospheric stratification conditions are subdivided into three cases according to Zhang and Anthes (1982) and the function forms are given by Eqs. (13), (14), and (15).

1. Strongly stable condition $\left(R i_{\mathrm{B}} \geq 0.2\right)$ :

$$
\psi_{\mathrm{M}}=\psi_{\mathrm{H}}=-10 \ln \frac{z}{z_{0}} .
$$

2. Weakly stable condition $\left(0<R i_{\mathrm{B}}<0.2\right)$ :

$$
\psi_{\mathrm{M}}=\psi_{\mathrm{H}}=-5\left(\frac{R i_{\mathrm{B}}}{1.1-5 R i_{\mathrm{B}}}\right) \ln \frac{z}{z_{0}} .
$$

3. Neutral condition $\left(R i_{\mathrm{B}}=0\right)$ :

$$
\psi_{\mathrm{M}}=\psi_{\mathrm{H}}=0
$$

4. Unstable condition $\left(R i_{\mathrm{B}}<0\right)$ :

$$
\begin{aligned}
& \psi_{M}=2 \ln \frac{1+x}{2}+\ln \frac{1+x^{2}}{2}-2 \arctan (x)+\frac{\pi}{2}, \\
& \psi_{\mathrm{H}}=2 \ln \frac{1+y}{2} \\
& \text { where } x=(1-16 \zeta)^{1 / 4}, y=(1-16 \zeta)^{1 / 2} .
\end{aligned}
$$

This scheme calculates turbulent fluxes of the momentum and sensible heat with $u_{*}$ and $\theta_{*}$. In order to avoid the huge difference between the two computations, $u_{*}$ is arithmetically averaged with its previous value by Eq. (17), and a lower limit of $u_{*}=0.1 \mathrm{~m} \mathrm{~s}^{-1}$ is imposed to prevent the heat flux from being zero under very stable conditions. According to the profile functions of wind and temperature near the ground, $\theta_{*}$ is then deduced by Eq. (18).

$$
\begin{aligned}
& u_{*}=\frac{1}{2}\left(u_{*}+\frac{k u}{\ln \frac{z}{z_{0 m}}-\psi_{\mathrm{M}}}\right), \\
& \theta_{*} \frac{k\left(\theta-\theta_{g}\right)}{R\left[\ln \frac{z}{z_{0 h}}-\psi_{\mathrm{H}}\right]} .
\end{aligned}
$$

The calculation procedure of the $\mathrm{Li}$ scheme is as follows: (1) determine $R i_{\mathrm{B}}, z_{0 m}$, and $z_{0 h}$ according to the observation data; (2) calculate $\zeta$ with $R i_{\mathrm{B}}, z_{0 m}$, and $z_{0 h}$; and (3) calculate the momentum and sensible heat fluxes under different conditions. The MM5 scheme is summarized as follows: (1) determine the universal functions according to the values of $R i_{\mathrm{B}}$ and $z_{0},(2)$ calculate the $u_{*}$ and $\theta_{*}$ with the meteorological variables and flux data, and (3) derive the turbulent fluxes. Compared with other non-iterative schemes including MM5, the Li scheme can be applied to the full range of roughness status $10 \leq \frac{z}{z_{0 m}} \leq 10^{5}$ and $-0.5 \leq \ln \frac{z_{0 m}}{z_{0 h}} \leq 30$ under whole conditions $-5 \leq R i_{\mathrm{B}} \leq 2.5$. In addition, there are three obvious differences between the Li and MM5 schemes: (1) Li distinguishes $z_{0 h}$ from $z_{0 m}$ but MM5 does not, (2) the two schemes apply different universal functions under stable conditions, and (3) Li considers the RSL effect while MM5 ignores it.

\section{Observational data and methods}

The observational fluxes used in this study were measured at Gucheng station from 1 December 2016 to 9 January 2017. Gucheng station $\left(115.40^{\circ} \mathrm{E}, 39.08^{\circ} \mathrm{N}\right)$ is located in Gucheng 

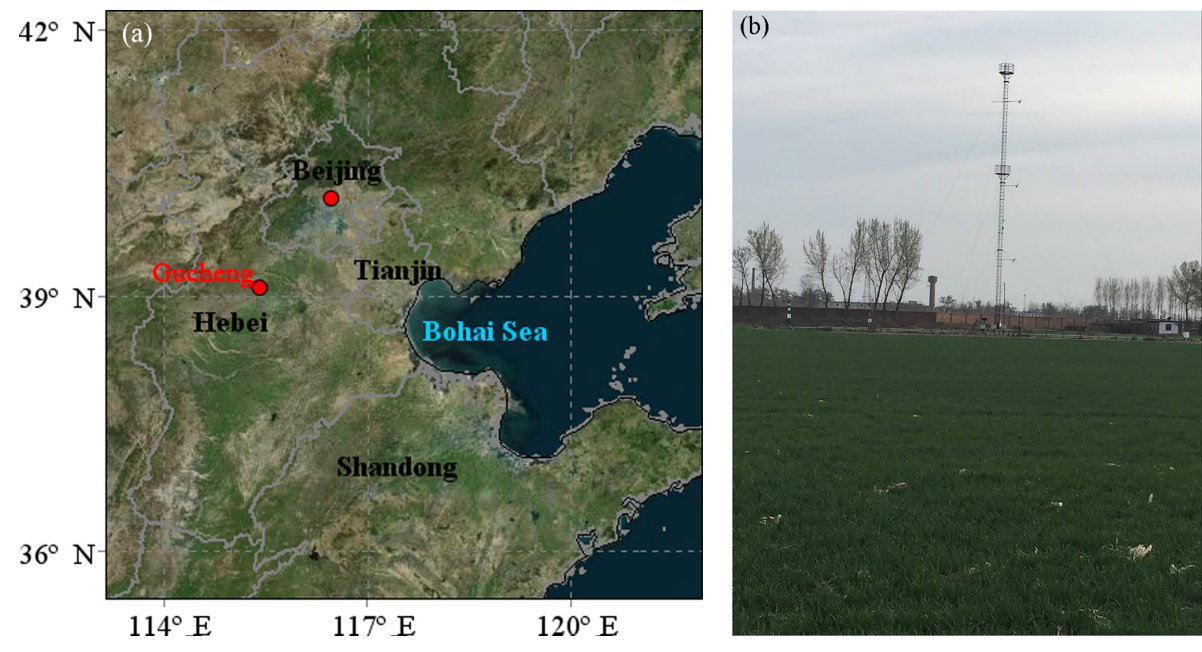

Figure 1. Location (a) and geographical environment (b) at Gucheng station. The map is from Bing Maps.

County, Baoding, Hebei Province, and it is about $110 \mathrm{~km}$ southwest of Beijing (Fig. 1a). This station is on a farmland site where rice is grown in summer and wheat in winter. The surroundings are mainly farmland and scattered villages (Fig. 1b). At Gucheng station, the momentum and sensible heat fluxes near the surface were measured by the eddy correlation flux measurement system. The system is mainly composed of a sonic anemometer (CSAT3) and a gas analyzer (LI-7500). They are set up at a height of $4 \mathrm{~m}$ above the ground surface. The measured fluxes are used to evaluate the two schemes as well as estimate the roughness lengths. The measured meteorological variables including wind speed and direction, temperature, humidity, pressure, and radiation are utilized to calculate the momentum and sensible heat fluxes both in the Li and MM5 schemes. Note the observed meteorological data were from Gucheng station and national basic automatic weather stations in Jing-Jin-Ji in eastern China, respectively. Hourly surface $\mathrm{PM}_{2.5}$ mass concentration in Baoding and Beijing from the China National Environmental Monitoring Centre (http://www.cnemc.cn/, last access: 14 October 2018) was also used in this paper.

\subsection{Data processing}

To obtain accurate flux data, quality control has been performed for the observational data, including (1) the elimination of the outliers and the data on rainy days, (2) double rotation and WPL correction (Webb et al., 1980), and (3) omission of the dataset when the wind speed is less than $0.5 \mathrm{~m} \mathrm{~s}^{-1}$. In addition, the wind field, especially the wind direction, has a great impact on the value of $z_{0 m}$, so it is necessary to understand the situation at Gucheng station. Figure 2 shows the distribution frequency of wind speed and wind direction at Gucheng during the observation (1 December 2016-9 January 2017). The wind speed is stable during this period and the maximum is no more than $5 \mathrm{~m} \mathrm{~s}^{-1}$, and most of them are

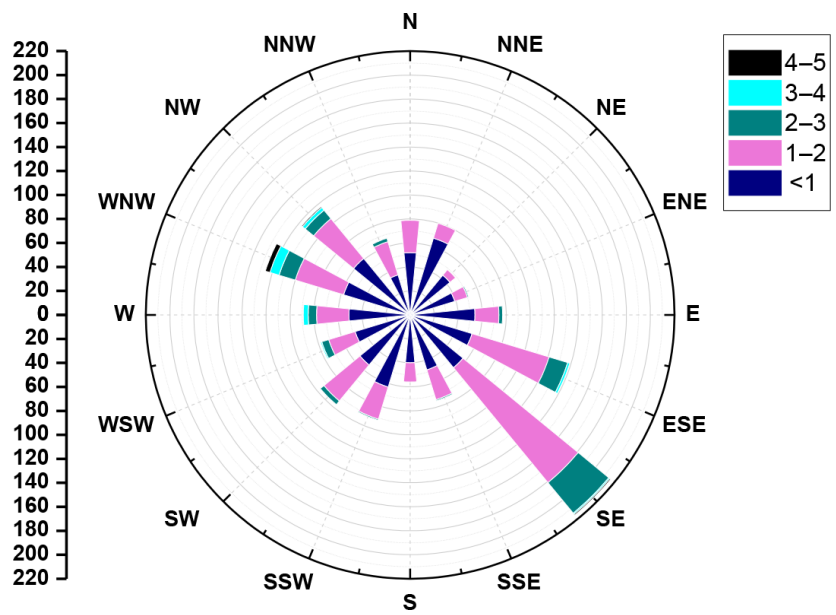

Figure 2. Wind rose map at Gucheng station from 1 December 2016 to 9 January 2017.

about $1-2 \mathrm{~m} \mathrm{~s}^{-1}$. The wind direction is relatively uniform except for the southeast wind $\left(135^{\circ}\right)$.

\subsection{Determination of surface skin temperature}

The surface skin temperature at Gucheng station is calculated from the radiation data by the following formula:

$R_{\mathrm{lw}}^{\uparrow}=\left(1-\varepsilon_{\mathrm{s}}\right) R_{\mathrm{lw}}^{\downarrow}+\varepsilon_{\mathrm{s}} \sigma T_{g}^{4}$,

where $R_{\mathrm{lw}}^{\uparrow}$ and $R_{\mathrm{lw}}^{\downarrow}$ are the surface upward longwave radiation and longwave radiation incident on the surface, respectively; $\sigma$ is the Stephen Boltzmann constant, $\sigma=5.67 \times$ $10^{-8} \mathrm{~W} \mathrm{~m}^{-2} \mathrm{~K}^{-4} . T_{g}$ is the surface skin temperature and $\varepsilon_{\mathrm{s}}$ is the surface emissivity, which is the prerequisite of $T_{g}$ calculation. Many research studies estimated the value of $\varepsilon_{\mathrm{s}}$ and found it is always 0.9-1 (Stewart et al., 1994; Verhoef et al., 1997). According to the semi-empirical method in Yang et 


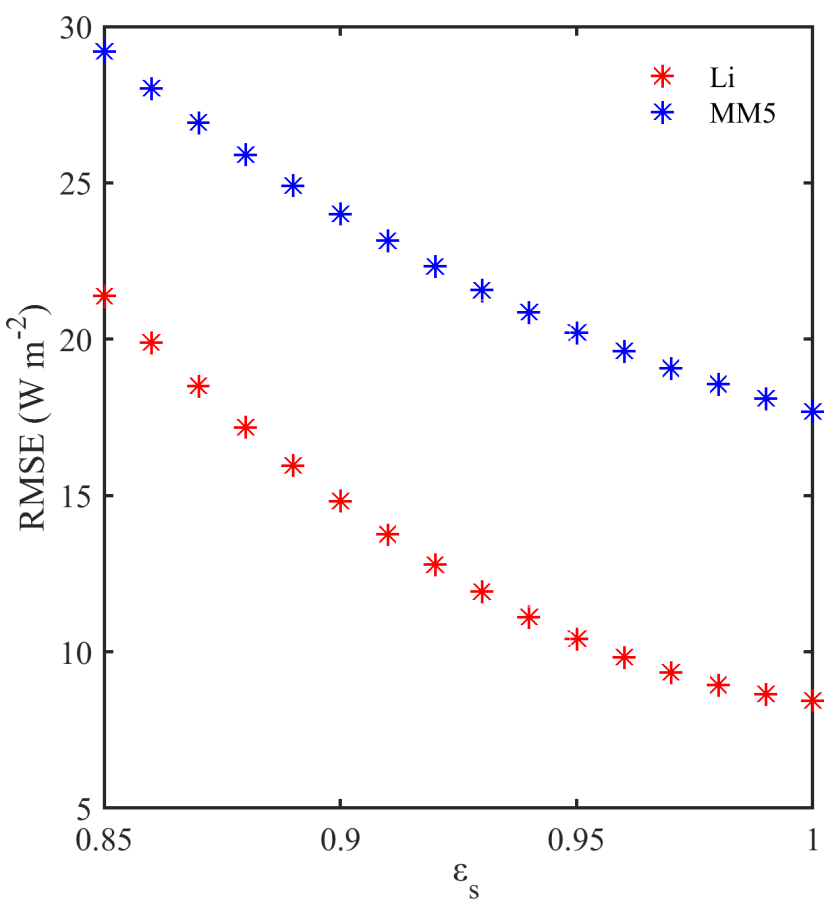

Figure 3. The surface emissivity $\varepsilon_{\mathrm{S}}$ dependence of RMSE between observed near-neutral heat fluxes and parameterized heat fluxes (red for Li and blue for MM5) at Gucheng station.

al. (2008), $\varepsilon_{\mathrm{S}}$ is estimated when the root mean square error (RMSE) is minimal. In this paper, the Li and MM5 schemes were used to estimate the $\varepsilon_{\mathrm{s}}$ value (as shown in Fig. 3). It is clear that the $\varepsilon_{\mathrm{S}}$ value corresponding to the minimum RMSE is not very sensitive to the choice of the two schemes. When $\varepsilon_{\mathrm{S}}$ is 1 , the RMSE has a minimum value. Thus, this experiment takes 1 as the optimal value of $\varepsilon_{\mathrm{s}}$.

\subsection{Determination of roughness length $z_{0 m}\left(z_{0 h}\right)$}

Using the observed momentum and sensible heat fluxes and the meteorological variables including wind speed, temperature, humidity, and pressure after quality control at Gucheng station, $z_{0 m}$ and $z_{0 h}$ were derived from Eq. $(20 \mathrm{a}, \mathrm{b})$ following Yang et al. (2003) and Sicart et al. (2014).

$$
\begin{aligned}
& \frac{u_{*}}{u}=\frac{k}{\ln \frac{z}{z_{0 m}}-\psi_{\mathrm{M}}}, \\
& \frac{\theta_{*}}{\left(\theta-\theta_{g}\right)}=\frac{k}{R\left[\ln \frac{z}{z_{0 h}}-\psi_{\mathrm{H}}\right]} .
\end{aligned}
$$

During the observation period, the crops stopped growing and the height did not exceed $0.1 \mathrm{~m}$, so the zero-plane displacement height was ignored and the reference height $z$ was taken as $4 \mathrm{~m}$. The observation time was too short (about 1 month) to consider the effect of seasonal variations on the roughness length. Thus, $z_{0 m}$ and $z_{0 h}$ were assumed to be two fixed values. Based on the variables and formulae mentioned
Table 1. Typical values of $z_{0 m}$ corresponding to various land-cover types.

\begin{tabular}{ll}
\hline$z_{0 m} / m$ & Land-cover types \\
\hline $5-50$ & Mountain (above $100 \mathrm{~m}$ ) \\
$1-5$ & Center of large cities, hills or mountain area \\
$0.1-1$ & Forests, the center of large towns \\
$0.01-0.1$ & Flat grasslands, agricultural fields \\
$10^{-4}-10^{-3}$ & Snow surface, wide water surface, flat deserts \\
$10^{-5}$ & Ice surface \\
\hline
\end{tabular}

above, the two roughness lengths at Gucheng are derived: $z_{0 m}=0.0419 \mathrm{~m}$ and $z_{0 h}=0.0042 \mathrm{~m}$.

\section{Results and discussion}

The definitions and influences of the RSL on the calculation of the turbulent flux are discussed in detail in this section. The Li and MM5 schemes are tested offline and evaluated during the haze pollution from 13 to 23 December 2016.

\subsection{The influences of the RSL and roughness length on the calculation of the turbulent flux}

The RSL is usually defined as the region where the flow is influenced by the individual roughness elements as reflected by the spatial inhomogeneity of the mean flow (Florens et al., 2013). In the RSL, turbulence is strongly affected by individual roughness elements, and standard MOST is no longer valid (Simpson et al., 1998). Therefore, it is necessary to consider the RSL effect in the calculation of the turbulent flux, especially for rough terrain such as forest or large cities. $z_{0 m}$ is defined as the height at which the extrapolated wind speed following the similarity theory vanishes. It is mainly determined by land-cover type and canopy height after excluding large obstructions. In models, $z_{0 m}$ is always based on the look-up table which is related to land-cover types. In this study, $z_{0 m}$ is simply classified based on the research of Stull (1988) and listed in Table 1. It can be seen in Table 1 that the rougher underlying surface corresponds to the larger value of $z_{0 m} . z_{0 h}$ is the height at which the extrapolated air temperature is identical to the surface skin temperature. Some early researchers assumed that $z_{0 m}$ was equal to $z_{0 h}$ (Louis, 1979; Louis et al., 1982). However, the assumption is not applicable in reality because $z_{0 m}$ and $z_{0 h}$ have different physical meanings. Different treatments of $z_{0 m}$ and $z_{0 h}$ may introduce considerable changes in the surface flux calculation (Launiainen, 1995; Kot and Song, 1998; Anurose and Subrahamanyam, 2013). Many studies removed the assumption that $z_{0 m}$ was equal to $z_{0 h}$ and made the schemes more applicable in the situation that $z_{0 m}$ was not equal to $z_{0 h}$ or the ratio of $z_{0 m}$ to $z_{0 h}$ was much larger (Wouters et al., 2012; Li et al., 2014, 2015). Some field experiments even indicated the ra- 
tio $z_{0 m} / z_{0 h}$ has a diurnal variation (Sun, 1999; Yang, 2003, 2008). In this study, we make the common assumption that the ratio $z_{0 m} / z_{0 h}$ is a constant.

Considering the lowest level in mesoscale models is usually about $10 \mathrm{~m}, z=10 \mathrm{~m}$ is set as the reference height in this study. The range of $R i_{\mathrm{B}}$ is set according to Louis et al. (1982) in the following discussion. Firstly, the study discusses the effects of different land-cover types (different $z_{0 m}$ values) and the RSL on flux calculation. Set $z_{0 m}=z_{0 h}$, corresponding to four cases: $z_{0 m}=1,0.5,0.05$, and $0.001 \mathrm{~m}$. These cases correspond to large cities, forests, agricultural fields, and wide water surface, respectively. Figure 4 shows the relationship between $C_{\mathrm{M}}\left(C_{\mathrm{H}}\right)$ and $R i_{\mathrm{B}}$ under different $z_{0 m}$ values and treatments of the RSL. It can be seen that both the RSL and $z_{0 m}$ have impacts on $C_{\mathrm{M}}$ and $C_{\mathrm{H}}$. Ignoring the RSL effect can result in larger $C_{\mathrm{M}}$ and $C_{\mathrm{H}}$ compared with the results of the original scheme considering the RSL effect. The difference induced by the RSL effect is only evident under the rough surface. For example, the difference under $z_{0 m}=1$ is obviously greater than other $z_{0 m}$ settings, and when $z_{0 m}$ is reduced to 0.05 or less, the RSL has little effect. Furthermore, the RSL contributes more to sensible heat transfer than to momentum transfer under the same setting of $z_{0 m}$. The effects of different land-cover types on $C_{\mathrm{M}}$ and $C_{\mathrm{H}}$ are much more significant compared with the RSL. The rougher surface (corresponding to the larger $z_{0 m}$ value) brings the larger $C_{\mathrm{M}}\left(C_{\mathrm{H}}\right)$ under the same stability. In addition, there is a corresponding relationship between $C_{\mathrm{M}}\left(C_{\mathrm{H}}\right)$ and stability. The value of $C_{\mathrm{M}}\left(C_{\mathrm{H}}\right)$ drops with stability. Once $R i_{\mathrm{B}}$ exceeds the critical value (generally $0.2-0.25$ ), the transfer coefficients decline sharply but are still above 0 .

Secondly, the effects of difference between $z_{0 m}$ and $z_{0 h}$ as well as the RSL on flux calculation are discussed. The relationship between $z_{0 m}$ and $z_{0 h}$ can be expressed as $k B^{-1}=$ $\ln \frac{z_{0 m}}{z_{0 h}}$. Over the sea, $z_{0 m}$ is comparable to $z_{0 h}$; over the uniform vegetation surface (e.g., grassland, farmland, woodland), $k B^{-1}$ is about $2\left(z_{0 m} / z_{0 h} \approx 10\right)$ (Garratt and Hicks, 1973; Garratt, 1978; Garratt and Francey, 1978), which coincides with our results in Gucheng $\left(z_{0 \mathrm{~m}}=0.0419 \mathrm{~m}, z_{0 h}=\right.$ $0.0042 \mathrm{~m}$ ); over the surface with bluff roughness elements, the $k B^{-1}$ value may be very large. For example, in some large cities, $k B^{-1}$ is even up to $30\left(z_{0 m} / z_{0 h} \approx 10^{13}\right)$ (Sugawara and Narita, 2009). Therefore, the ratio $z_{0 m} / z_{0 h}$ varies over a wide range. Figure 5 shows the relationship between $C_{\mathrm{M}}\left(C_{\mathrm{H}}\right)$ and $R i_{\mathrm{B}}$ under different treatments of $z_{0 \mathrm{~m}} / z_{0 h}$. Set $z_{0 m}=1$ as a large city case, $z_{0 h}=1,0.01,10^{-4}$, and $10^{-6} \mathrm{~m}$, and the large differences derived from the different ratios are displayed in Fig. 5. The differences induced by the RSL effect are more obvious than those in Fig. 4. The different treatments of ratio $z_{0 m} / z_{0 h}$ have great impacts on turbulent flux transfer, particularly for sensible heat transfer. It seems evident that when $z_{0 h}$ is not equal to $z_{0 m}\left(z_{0 m} / z_{0 h}=100-10^{6}\right)$, the calculated $C_{\mathrm{H}}$ is much smaller compared to the treatment when $z_{0 h}$ is equal to $z_{0 m}\left(z_{0 m} / z_{0 h}=1\right)$. In addition, $C_{\mathrm{M}}\left(C_{\mathrm{H}}\right)$ decreases with stability, and it decreases much slower when $z_{0 h}$ is not equal to $z_{0 m}$.

\subsection{Comparison of momentum and sensible heat fluxes calculated by the two schemes}

Using the obtained roughness lengths and the observations, the momentum and sensible heat fluxes were calculated by the Li and MM5 schemes. Firstly, $z_{0 m}$ and $z_{0 h}$ were set as 0.0419 and 0.0042 , respectively, in the Li scheme, and $z_{0}$ was equal to $z_{0 m}$ in the MM5 scheme, to calculate the momentum and sensible heat fluxes, and the results are shown in Fig. 6a and b. It can be seen that compared with MM5, Li performs better with a higher regression coefficient and determination coefficient. For the momentum fluxes, the regression coefficient by $\mathrm{Li}$ is 0.6795 and that by MM5 is 0.5598 , indicating that the error of Li is $12 \%$ lower than that of MM5. For sensible heat fluxes, the regression coefficient by $\mathrm{Li}$ is 0.7967 and that by MM5 is 1.7994 . The latter is much larger than 1; that is, the MM5 scheme obviously overestimates the sensible heat due to it not distinguishing $z_{0 h}$ from $z_{0 m}$. Then, $z_{0}$ is made equal to 0.0042 in the MM5 scheme to recalculate the sensible heat flux, and the result is shown in Fig. 6c. It can be seen that the result has a great improvement after modifying the $z_{0}$ value, and the regression coefficient by MM5 is 0.7363 , indicating that the error was reduced by $54 \%$ after considering the $z_{0 h}$ effect. The result indicates that $z_{0 h}$ plays a critical role in both the SL scheme and the sensible heat flux (Chen and Zhang, 2009; Chen et al., 2011). However, the error of MM5 is still 6\% larger than that of Li. This illustrates that in addition to the effect of roughness length, the algorithm of the Li scheme itself is more reasonable than that of the MM5 scheme.

\subsection{The specific performance of the two schemes in severe haze pollution}

There were two obvious pollution processes during this observation period, and one occurred during 13 to 23 December 2016. Figure 7 shows the variations of hourly observed $\mathrm{PM}_{2.5}$ concentration as well as the momentum and sensible heat fluxes calculated by the Li and MM5 schemes at Gucheng station in this process. For research purposes, only the daytime (from 08:00 to 20:00) was taken into account. Note that in MM5, $z_{0}$ was 0.0419 when calculating momentum fluxes and it was 0.0042 when calculating sensible heat fluxes. As shown in Fig. 7, the calculated results of momentum and sensible heat fluxes by the two schemes are generally consistent with the trend of the observations. Specifically, for the momentum fluxes (Fig. 7a), the results of two schemes have little difference when the values of observed momentum fluxes are large or at the peak. When the observed momentum fluxes are small, Li results are close to or less than the observations, while MM5 results are always higher than observations because of the limit of $u_{*}=0.1$ in 

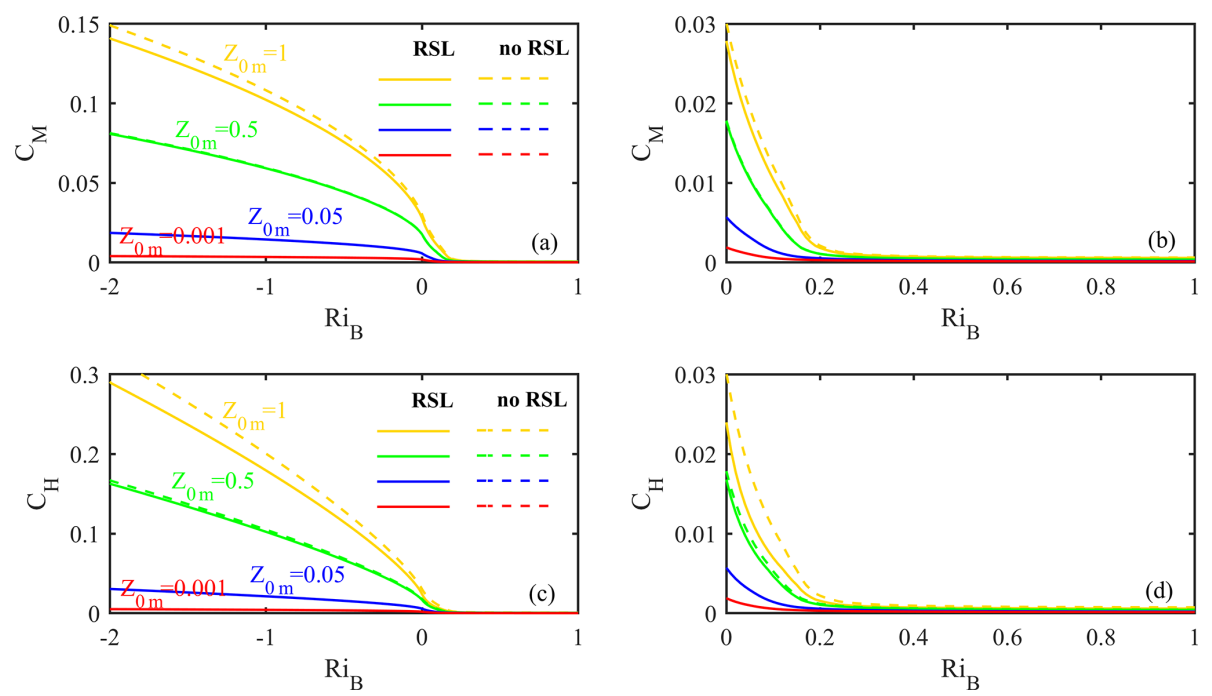

Figure 4. The relationships between $C_{\mathrm{M}}\left(C_{\mathrm{H}}\right)$ and $R i_{\mathrm{B}}$ under different $z_{0 m}$ values and treatments of the RSL. Solid lines: considering the RSL effect; dotted lines: without the RSL effect.
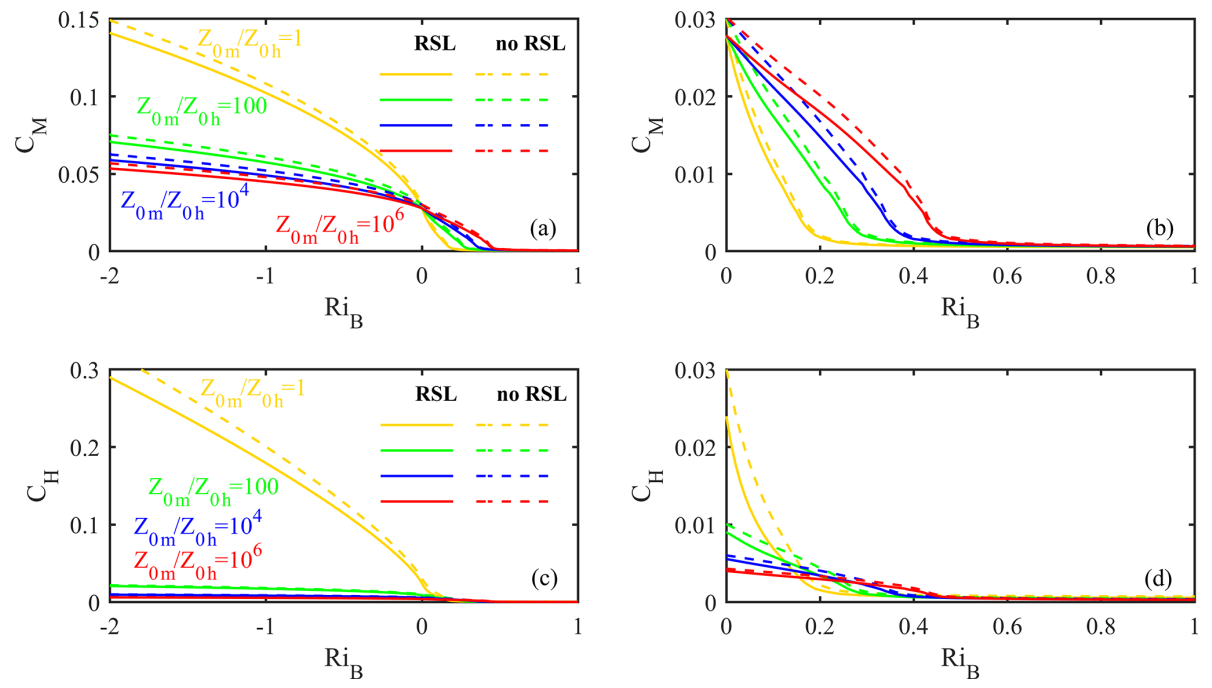

Figure 5. The relationships between $C_{\mathrm{M}}\left(C_{\mathrm{H}}\right)$ and $R i_{\mathrm{B}}$ under different ratios of $z_{0 m}$ to $z_{0 h}$ and treatments of the RSL. Solid lines: considering the RSL effect; dotted lines: without the RSL effect.

this scheme. For the sensible heat flux (Fig. 7b), MM5 results are always lower, while Li results are closer to observations, especially when the observed values are small. Furthermore, according to the evolution of $\mathrm{PM}_{2.5}$ concentration, this haze event was then divided into three stages: the clear stage (stage 1: 13-14), the transition stage (stage 2: 16-18), and the maintenance stage (stage 3: 21-22). As shown in Fig. 7, in the clear stage (stage 1), the atmospheric stratification is unstable, $\mathrm{PM}_{2.5}$ concentration is low, and there is a strong flux transport in the SL; the corresponding observations of the momentum and sensible heat fluxes are relatively high and they vary greatly. In the transition stage (stage 2), the atmosphere is changing from being unstable to stable, corresponding to haze formation; the momentum and sen- sible heat fluxes gradually decrease; and the daily variation also decreases. In the maintenance stage (stage 3), the atmospheric stratification is very stable, flux transport in the SL is weak, and both the momentum and sensible heat fluxes are at a low level. It can be seen that the Li results are generally closer to the observations compared with MM5 results in all three stages.

Figure 8 shows the probability distribution functions (PDFs) of the difference between calculated fluxes (using the $\mathrm{Li}$ and MM5 schemes) and observations in different stages at Gucheng station. In the whole pollution process, for the momentum fluxes (Fig. 8a), the PDF from Li tends to cluster in a narrower range centered by 0 , and the probability within $\pm 0.005 \mathrm{Nm}^{-2}$ is $46.82 \%$, while this value from 

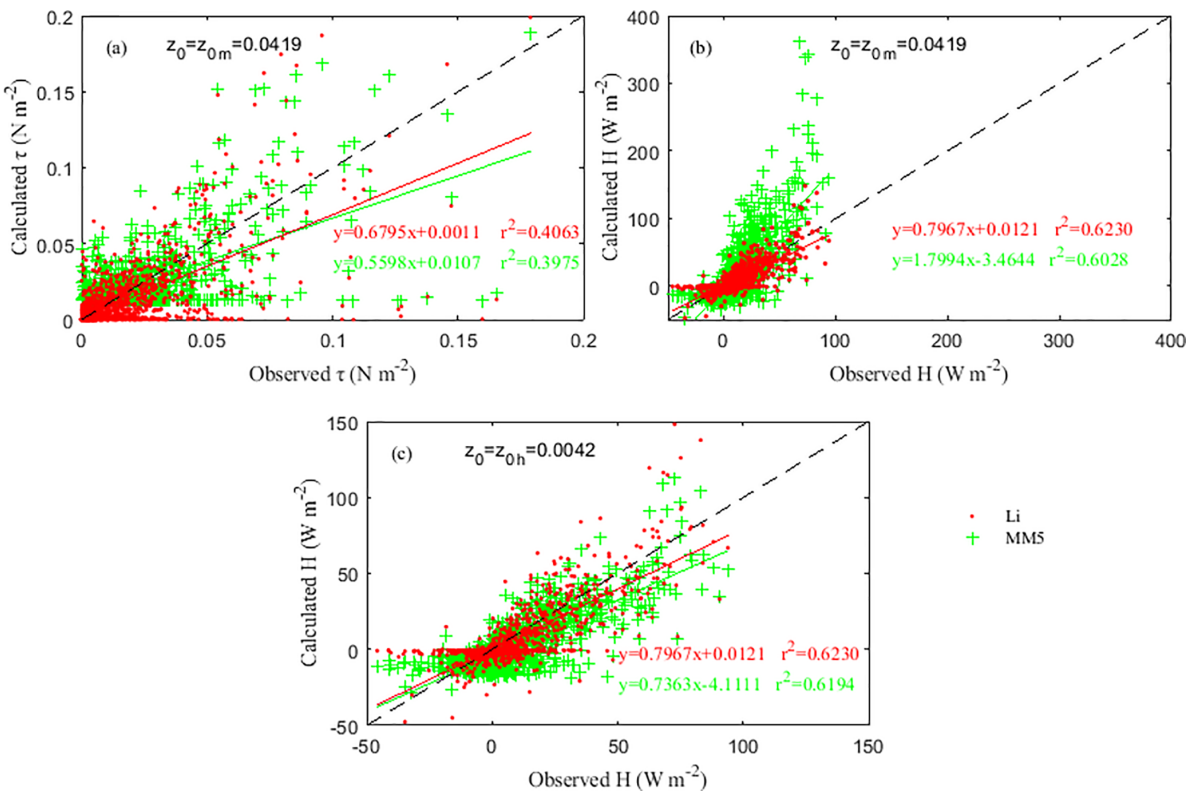

Figure 6. Comparison of calculated and observed fluxes at Gucheng station from 1 December 2016 to 9 January 2017. (a) Momentum fluxes (MM5: $\left.z_{0}=0.0419\right)$; (b) sensible heat fluxes (MM5: $\left.z_{0}=0.0419\right)$; (c) sensible heat fluxes (MM5: $\left.z_{0}=0.0042\right)$. Red dots: the Li scheme; green plus signs: the MM5 scheme.

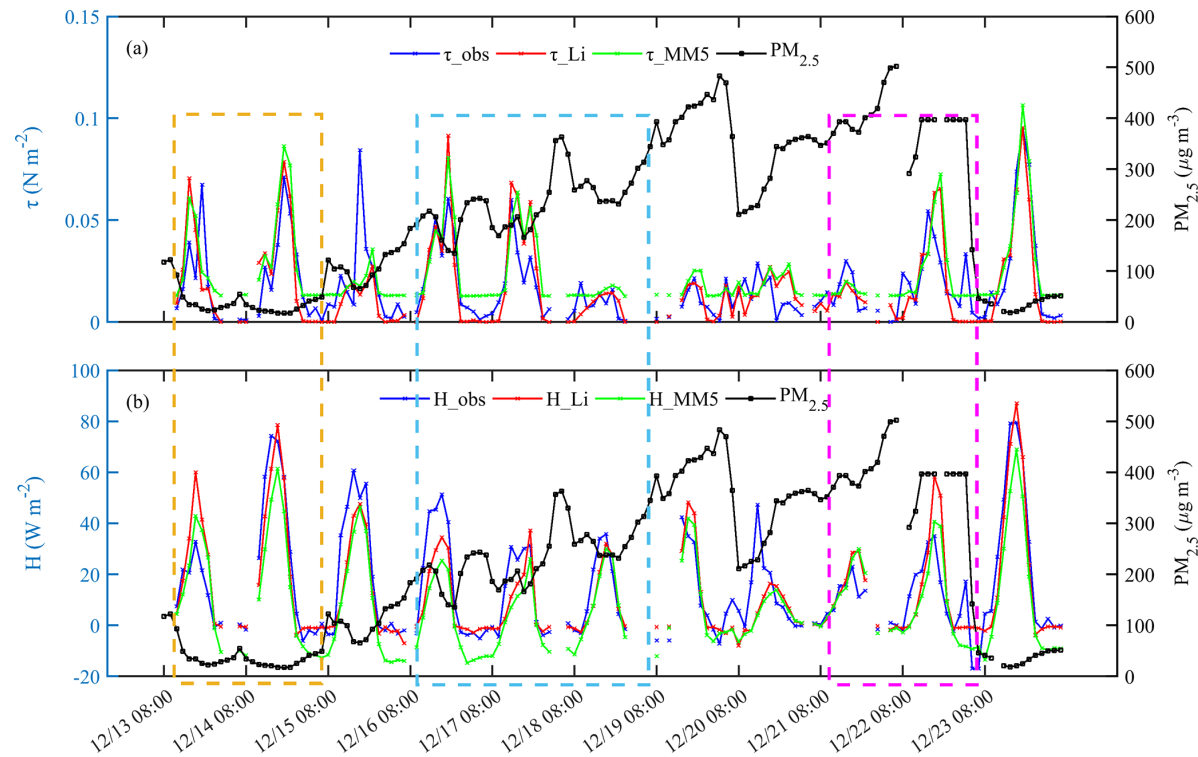

Figure 7. Variations of hourly turbulent fluxes and observed $\mathrm{PM}_{2.5}$ at Gucheng station in daytime. (a) Momentum fluxes $\tau$ (blue line: observations; red line: the Li scheme; green line: the MM5 scheme) and $\mathrm{PM}_{2.5}$ concentration (black line); (b) sensible heat fluxes $H$ (the same as $\tau$ ) and $\mathrm{PM}_{2.5}$ concentration (black line). Yellow box: stage 1; blue box: stage 2; purple box: stage 3 .

MM5 falls to $23.02 \%$. For the sensible heat fluxes (Fig. 8b), the PDF from $\mathrm{Li}$ is also more concentrated around 0 than that from MM5. The probabilities of bias from $\mathrm{Li}$ and MM5 within $\pm 2.5 \mathrm{~W} \mathrm{~m}^{-2}$ are $32.54 \%$ and $13.49 \%$, respectively. In stage 1 , for the momentum fluxes (Fig. 8c), the probability of bias from $\mathrm{Li}$ within $\pm 0.005 \mathrm{Nm}^{-2}$ is $38.09 \%$. The bias from MM5 is mainly larger than 0 , and the prob- ability within $\pm 0.005 \mathrm{Nm}^{-2}$ is $14.29 \%$. For the sensible heat fluxes (Fig. 8d), the probability of bias from $\mathrm{Li}$ within $\pm 2.5 \mathrm{~W} \mathrm{~m}^{-2}$ is $38.09 \%$, the same as momentum fluxes. The bias from MM5 is mainly less than 0 , and the probability within $\pm 2.5 \mathrm{~W} \mathrm{~m}^{-2}$ is $9.52 \%$. In stage 2 , the differences between the two schemes are more obvious. The PDFs from $\mathrm{Li}$ are the most concentrated around 0 in all cases, while 

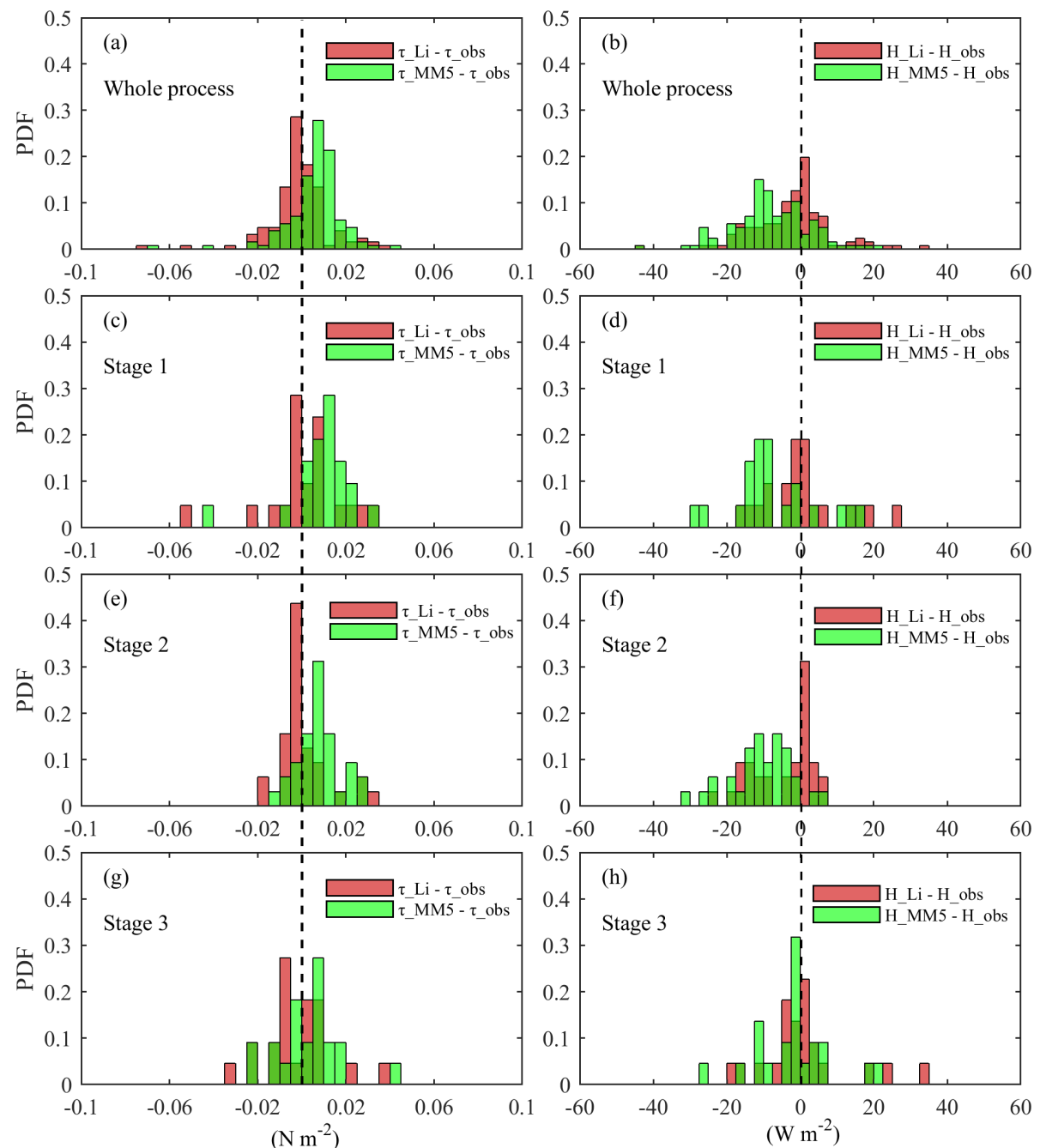

Figure 8. Probability distribution functions (PDFs) of the differences between calculated fluxes (momentum fluxes: left; sensible heat fluxes: right) using two schemes (the Li scheme: red bars; the MM5 scheme: green bars) and for observations in different stages (a, b: whole process; c, d: stage 1; e, f: stage 2; $\mathbf{g}, \mathbf{h}$ : stage 3$)$.

those from MM5 are similar to stage 1. Specifically, for the momentum fluxes (Fig. 8e), the probabilities of bias from $\mathrm{Li}$ and MM5 within $\pm 0.005 \mathrm{Nm}^{-2}$ are $56.25 \%$ and $25.00 \%$. For the sensible heat fluxes (Fig. 8f), the values within $\pm 2.5 \mathrm{~W} \mathrm{~m}^{-2}$ are $40.62 \%$ and $6.25 \%$. In stage 3 , the difference between the two schemes is small. For the momentum fluxes (Fig. 8g), the probabilities of bias from $\mathrm{Li}$ and MM5 within $\pm 0.005 \mathrm{Nm}^{-2}$ are $22.73 \%$ and $27.27 \%$. For the sensible heat fluxes (Fig. 8h), the values from $\mathrm{Li}$ and MM5 within $\pm 2.5 \mathrm{~W} \mathrm{~m}^{-2}$ are both $36.36 \%$.

Mean bias (MB), normalized mean bias (NMB), normalized mean error (NME), and root mean square error (RMSE) were calculated to test the results of the two schemes. Table 2 shows that the Li scheme generally estimates better than the MM5 scheme. In the whole haze process, the Li scheme underestimates the momentum fluxes by $3.63 \%$ relative to the observations, while the MM5 scheme overestimates the mo- mentum fluxes by $34.03 \%$. The Li and MM5 schemes underestimate the sensible heat fluxes by $15.69 \%$ and $50.22 \%$, respectively. In the three stages, the Li scheme performs much better than the MM5 scheme in stage 1 and stage 2; especially in stage 2 when atmospheric stratification transforms from unstable to stable conditions, the difference between the Li and MM5 schemes is particularly significant. That is, the Li and MM5 schemes overestimate the momentum fluxes by $7.68 \%$ and $45.56 \%$, respectively, and they underestimate the sensible heat fluxes by $33.84 \%$ and $76.88 \%$. The error of $\mathrm{Li}$ is much less than that of MM5. In view of the important role of atmospheric stratification in the generation and accumulation of $\mathrm{PM}_{2.5}$ in stage 2, the $\mathrm{Li}$ scheme is expected to show better performance in the online simulation of $\mathrm{PM}_{2.5}$ than MM5.

Based on the good behavior of the Li scheme in Gucheng, the same experiment was performed at Beijing station to 
Table 2. Statistics between the Li and MM5 schemes of the calculated turbulent flux at Gucheng station.

\begin{tabular}{llrrrr|rrrr}
\hline & & \multicolumn{3}{c}{$\mathrm{Li}$} & & \multicolumn{3}{c}{ MM5 } \\
\cline { 2 - 9 } & & $\mathrm{MB}$ & NMB & NME & RMSE & \multirow{2}{*}{ MB } & NMB & NME & RMSE \\
\hline \multirow{2}{*}{ Whole process } & $\tau$ & -0.0006 & $-3.63 \%$ & $54.29 \%$ & 0.0142 & 0.0058 & $34.03 \%$ & $63.59 \%$ & 0.0143 \\
& $H$ & -2.2723 & $-15.69 \%$ & $52.73 \%$ & 10.9649 & -7.2735 & $-50.22 \%$ & $69.68 \%$ & 12.7946 \\
Stage 1 & $\tau$ & 0.0021 & $9.98 \%$ & $55.90 \%$ & 0.0172 & 0.0091 & $43.45 \%$ & $66.66 \%$ & 0.0169 \\
& $H$ & 1.1775 & $5.79 \%$ & $37.87 \%$ & 10.5734 & -7.1891 & $-35.34 \%$ & $55.70 \%$ & 13.1324 \\
Stage 2 & $\tau$ & 0.0013 & $7.68 \%$ & $44.50 \%$ & 0.0111 & 0.0079 & $45.56 \%$ & $56.81 \%$ & 0.0121 \\
& $H$ & -4.5752 & $-33.84 \%$ & $50.28 \%$ & 9.3995 & -10.3924 & $-76.88 \%$ & $81.40 \%$ & 13.2553 \\
Stage 3 & $\tau$ & -0.0024 & $-13.25 \%$ & $59.13 \%$ & 0.0144 & 0.0030 & $16.72 \%$ & $56.34 \%$ & 0.0138 \\
& $H$ & 1.2818 & $11.39 \%$ & $66.31 \%$ & 11.4778 & -1.7479 & $-15.52 \%$ & $65.90 \%$ & 10.4219 \\
\hline
\end{tabular}

$\tau$ : momentum flux; $H$ : sensible heat flux; MB: mean bias; NMB: normalized mean bias; NME: normalized mean error; RMSE: root mean square error. The units of MB and RMSE are $\mu \mathrm{g} \mathrm{m}^{-3}$.

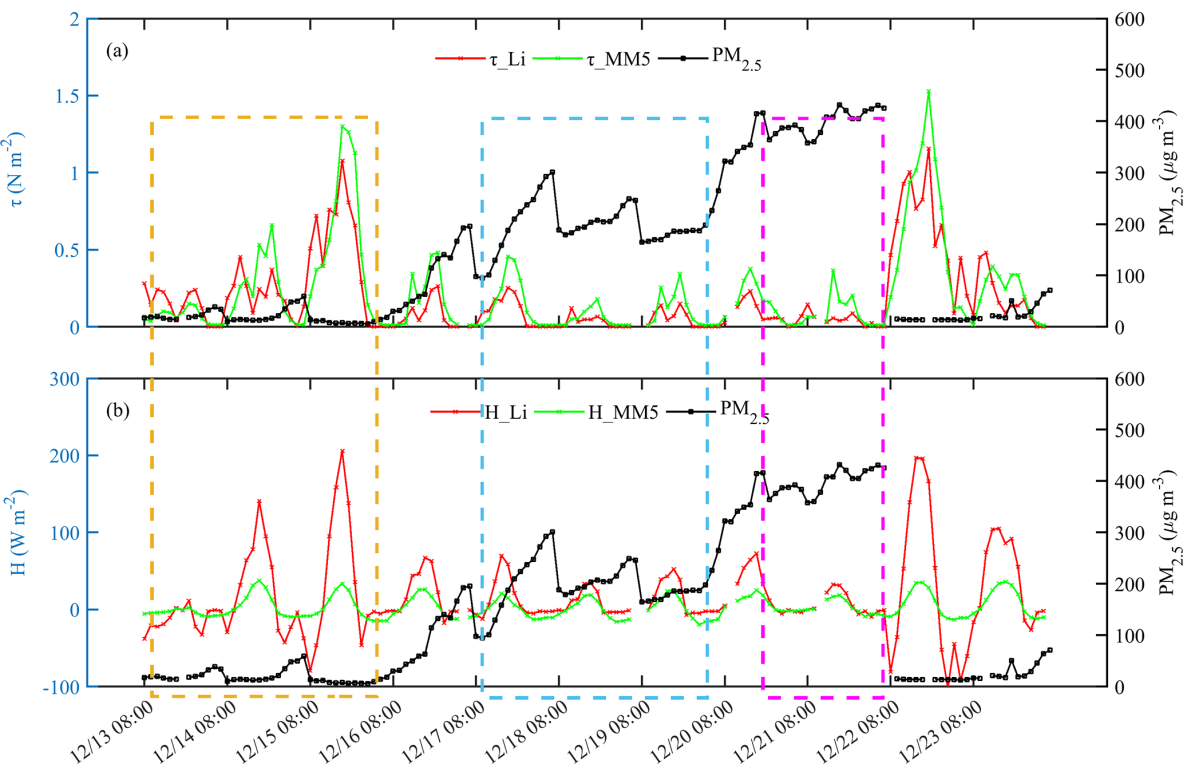

Figure 9. As in Fig. 7 but for Beijing station.

discuss the effect of different land-cover types on flux calculation. For Beijing station, the assumption $z_{0 m}=1 \mathrm{~m}$, $z_{0 m} / z_{0 h}=10^{6}$ was made to represent the surface conditions of the megacity due to a lack in situ measurements of surface turbulent flux. As shown in Fig. 9, the evolution of $\mathrm{PM}_{2.5}$ concentration at Beijing station was also divided into three stages (stage 1: 13-15; stage 2: 17-19; stage 3: 20-21), like Gucheng shown in Fig. 7. Compared with Gucheng, the momentum transfer at Beijing station is obviously larger due to a great increase of the urban aerodynamic roughness length $\left(z_{0 m}\right)$. Meanwhile, the difference between Li and MM5 is greater at Beijing station. The sensible heat transfer of the $\mathrm{Li}$ scheme shows a great difference between clear days and pollution days; that is, the sensible heat transfer changes acutely in stage 1 , while it changes smoothly in stage 2 and stage 3 . However, the result of the MM5 scheme is significantly different from the Li result due to MM5 ignoring the $z_{0 m}$ effect, and the small number of $z_{0 h}$ keeps the sensible heat fluxes at a low level in all three stages.

To quantify the difference between the two schemes, a relative difference is defined as a percentage:

$\Delta V=\left|\frac{V_{\mathrm{Li}}-V_{\mathrm{MM} 5}}{V_{\mathrm{MM} 5}}\right| \times 100 \%$,

where $V_{\mathrm{Li}}$ and $V_{\mathrm{MM} 5}$ are the momentum (or sensible heat) fluxes calculated by the Li and MM5 schemes, respectively. We obtained the relative differences at the two stations in the three stages through the statistics. It is clear that the largest relative difference at Gucheng station is in stage 2 and at Beijing station it is in stage 1. The differences in Beijing are always larger than those in Gucheng for each of the three stages. Specifically, the relative differences of the momentum flux in stage 1 , stage 2 , and stage 3 increase by $73 \%$, 

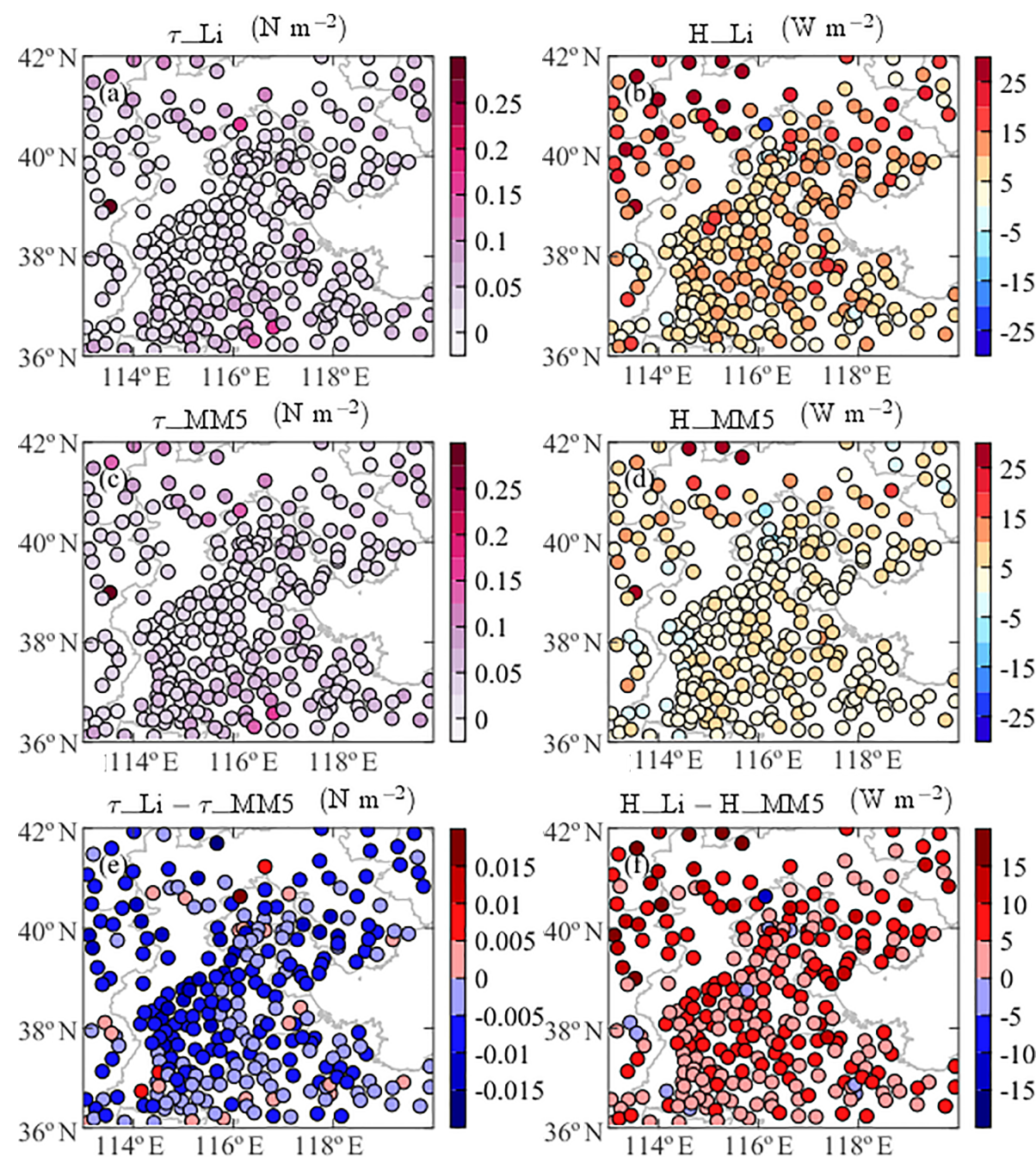

Figure 10. The mean momentum and sensible heat fluxes calculated using two schemes (a, b: the Li scheme; c, d: the MM5 scheme) and their differences (Li minus MM5. e: momentum fluxes; f: sensible heat fluxes) in Jing-Jin-Ji during the haze episode (13 to 23 December 2016 ).

$34 \%$, and $27 \%$, respectively, and the results of the sensible heat flux are $289 \%, 52 \%$, and $68 \%$, respectively.

We further estimated the surface fluxes in the whole JingJin-Ji region using the two schemes. Figure 10 shows the mean momentum and sensible heat fluxes calculated by the $\mathrm{Li}$ and MM5 schemes and their differences in Jing-Jin-Ji during the pollution episode. The assumption $\left(z_{0 m}=0.1 \mathrm{~m}\right.$, $z_{0 m} / z_{0 h}=10^{3}$ ) was used to represent the average conditions of the underlying surface of the Jing-Jin-Ji region. As shown in Fig. 10, the momentum fluxes calculated by $\mathrm{Li}$ are less than those by MM5 in most stations; the sensible heat fluxes calculated by Li are usually larger than those by MM5. The result is consistent with the experiment at Gucheng station, which further indicates the importance of considering both $z_{0 m}$ and $z_{0 h}$.

\section{Conclusions}

Using the observed momentum and sensible heat fluxes, together with conventional meteorological data including pressure, temperature, humidity, and wind speed from 1 December 2016 to 9 January 2017, including a severe pollution episode from 13 to 23 December 2016, the differences between the $\mathrm{Li}$ and MM5 schemes and the specific performances of the two were discussed and evaluated in this paper. The evolution process of atmospheric stratification from unstable to stable conditions corresponding to $\mathrm{PM}_{2.5}$ accumulation was mainly discussed. The contributions of roughness lengths $\left(z_{0 m}\right.$ and $\left.z_{0 h}\right)$ as well as other factors in the SL schemes to the flux calculation for the momentum and sensible heat were also discussed in detail. The results are summarized as follows:

1. $z_{0 m}$ and $z_{0 h}$ have important effects on turbulent flux calculation in the SL schemes. Different values of $z_{0 m}$ 
and $z_{0 h}$ could induce great changes in the flux calculation, indicating that it is very necessary and important to distinguish $z_{0 h}$ from $z_{0 m}$. Ignoring the difference between the two in the MM5 scheme led to large error in the calculation of the sensible heat flux, and this error in Gucheng was $54 \%$. Besides the roughness length, the algorithms in schemes are also important factors. In addition, ignoring the effect of the RSL in schemes may also result in certain bias of momentum and sensible heat fluxes in megacity regions which represent the rough underlying surface.

2. The effect of $z_{0 m} / z_{0 h}$ on turbulent fluxes is closely related to land-cover types $\left(z_{0 m}\right)$. A rough land-cover type (large $z_{0 m}$ ) should be accompanied by a large value of $z_{0 m} / z_{0 h}$. The differences between the two schemes for the momentum and sensible heat fluxes in Beijing were much larger than those in Gucheng. This suggests that the MM5 scheme probably induces greater error in megacities with a rough surface (e.g., Beijing) than in suburban areas with a smooth surface (e.g., Gucheng) due to the irrational algorithm of the MM5 scheme itself and the fact that the difference between $z_{0 m}$ and $z_{0 h}$ is ignored.

3. The Li scheme generally performed better than the MM5 scheme in the calculation of both the momentum flux and the sensible heat flux at Gucheng station. The Li scheme described atmospheric stratification, which is closely related to haze pollution, better compared with the MM5 scheme. This advantage was the most prominent in the transition stage from unstable to stable atmospheric stratification, corresponding to the $\mathrm{PM}_{2.5}$ accumulation. In this stage, the momentum flux calculated by $\mathrm{Li}$ was overestimated by $7.68 \%$ and this overestimation by MM5 was up to $45.56 \%$; the sensible heat flux by $\mathrm{Li}$ was underestimated by $33.84 \%$ while this underestimation by MM5 was as much as $76.88 \%$. In most of the Jing-Jin-Ji region, the momentum fluxes calculated by Li were less than those by MM5 and the sensible heat fluxes by Li were larger than those by MM5, which is consistent with Gucheng.

The offline study of the two SL schemes in this paper showed the superiority of the $\mathrm{Li}$ scheme for surface flux calculation corresponding to the $\mathrm{PM}_{2.5}$ evolution during haze episodes in Jing-Jin-Ji in eastern China. The study results offer a prerequisite and a possible way to improve PBL diffusion simulation and then $\mathrm{PM}_{2.5}$ prediction, which will be achieved in the follow-up work of integrating the $\mathrm{Li}$ scheme into atmosphere chemical models.

Data availability. Data used in this paper can be provided by Yue Peng (nuist_py@163.com) upon request.
Author contributions. HW and YP conducted the study design. YL and CL provided the Li scheme and the flux data. CL helped with data processing. YP wrote the manuscript with the help of $\mathrm{HW}$ and TZ. XZ, ZG, TJ, HC, and MZ were involved in the scientific interpretation and discussion. All the authors commented on the paper.

Competing interests. The authors declare that they have no conflict of interest.

Special issue statement. This article is part of the special issue "Regional transport and transformation of air pollution in eastern China". It is not associated with a conference.

Acknowledgements. The study was supported by the National Key Project (2016YFC0203306, 2016YFC0203304), the National (Key) Basic Research and Development (973) Program of China (2014CB441201), the National Natural Science Foundation of China (41505004, 41675009), and Jiangsu Provincial Natural Science Fund Project (BK20150910).

Edited by: Zhanqing Li

Reviewed by: three anonymous referees

\section{References}

Anurose, T. J. and Subrahamanyam, D. B.: Improvements in Sensible Heat-Flux Parametrization in the High-Resolution Regional Model (HRM) Through the Modified Treatment of the Roughness Length for Heat, Bound.-Lay. Meteorol., 147, 569-578, https://doi.org/10.1007/s10546-013-9799-9, 2013.

Ban, J., Gao, Z., and Lenschow, D. H.: Climate simulations with a new air-sea turbulent flux parameterization in the National Center for Atmospheric Research Community Atmosphere Model (CAM3), J. Geophys. Res.-Atmos., 115, D01106, https://doi.org/10.1029/2009JD012802, 2010.

Beljaars, A. C. M. and Holtslag, A. A. M.: Flux parameterization over land surfaces for atmospheric models, J. Appl. Meteor., 30, 327-341, 1991.

Businger, J. A.: Transfer of momentum and heat in the planetary boundary layer, Proc. Symp. Arctic Heat Budget and Atmospheric Circulation, RM-5233-NSF, 305-331, 1966.

Businger, J. A., Wyngaard, J. C., Izumi, Y., and Bradley, E. F.: Fluxprofile relationships in the atmospheric surface layer, J. Atmos. Sci., 28, 181-189, 1971.

Chen, F. and Zhang, Y.: On the coupling strength between the land surface and the atmosphere: From viewpoint of surface exchange coefficients, Geophys. Res. Lett., 36, L10404, https://doi.org/10.1029/2009GL037980, 2009.

Chen, Y., Yang, K., He, J., Qin, J., Shi, J., Du, J., and He, Q.: Improving land surface temperature modeling for dry land of China, J. Geophys. Res.-Atmos., 116, D20104, https://doi.org/10.1029/2011JD015921, 2011.

Cheng, F. Y., Chin, S. C., and Liu, T. H.: The role of boundary layer schemes in meteorological and air quality simu- 
lations of the Taiwan area, Atmos. Environ., 54, 714-727, https://doi.org/10.1016/j.atmosenv.2012.01.029, 2012.

Cheng, Y. and Brutsaert, W.: Flux-profile relationships for wind speed and temperature in the stable atmospheric boundary layer, Bound.-Lay. Meteorol., 114, 519-538, https://doi.org/10.1007/s10546-004-1425-4, 2005.

De Ridder, K.: Bulk Transfer Relations for the Roughness Sublayer, Bound.-Lay. Meteorol., 134, 257-267, https://doi.org/10.1007/s10546-009-9450-y, 2010.

Dyer, A. J.: The turbulent transport of heat and water vapour in an unstable atmosphere, Q. J. Roy. Meteorol. Soc., 93, 501-508, https://doi.org/10.1002/qj.49709339809, 1967.

Dyer, A. J.: A review of flux-profile relationships, Bound.-Lay. Meteorol., 7, 363-372, https://doi.org/10.1007/BF00240838, 1974.

Florens, E., Eiff, O., and Moulin, F.: Defining the roughness sublayer and its turbulence statistics, Exp. Fluids, 54, 1500, https://doi.org/10.1007/s00348-013-1500-z, 2013.

Garratt, J. R.: Transfer characteristics for a heterogeneous surface of large aerodynamic roughness, Q. J. Roy. Meteorol. Soc., 104, 491-502, 1978.

Garratt, J. R. and Francey, R. J.: Bulk characteristics of heat transfer in the unstable, baroclinic atmospheric boundary layer, Bound.-Lay. Meteorol., 15, 399-421, https://doi.org/10.1007/BF00120603, 1978.

Garratt, J. R. and Hicks, B. B.: Momentum, heat and water vapour transfer to and from natural and artificial surfaces, Q. J. Roy. Meteorol. Soc., 99, 680-687, 1973.

Högström, U.: Review of some basic characteristics of the atmospheric surface layer, Bound.-Lay. Meteorol., 78, 215-246, https://doi.org/10.1007/BF00120937, 1996.

Holtslag, A. A. M. and De Bruin, H. A. R.: Applied modeling of the nighttime surface energy balance over land, J. Appl. Meteorol., 27, 689-704, 1988.

Hu, X. M., Nielsen-Gammon, J. W., and Zhang, F.: Evaluation of three planetary boundary layer schemes in the WRF model, J. Appl. Meteorol. Climatol, 49, 1831-1844, https://doi.org/10.1175/2010JAMC2432.1, 2010.

Jiménez, P. A., Dudhia, J., González-Rouco, J. F., Navarro, J., Montávez, J. P., and García-Bustamante, E.: A revised scheme for the WRF surface layer formulation, Mon. Weather Rev., 140, 898918, https://doi.org/10.1175/MWR-D-11-00056.1, 2012.

Kot, S. C. and Song, Y.: An Improvement of the Louis Scheme for the Surface Layer in an Atmospheric Modelling System, Bound.-Lay. Meteorol., 88, 239-254, https://doi.org/10.1023/A:1001119329423, 1998.

Launiainen, J.: Derivation of the relationship between the Obukhov stability parameter and the bulk Richardson number for flux-profile studie, Bound.-Lay. Meteorol., 76, 165-179, https://doi.org/10.1007/BF00710895, 1995.

Li, T., Wang, H., Zhao, T., Xue, M., Wang, Y., Che, H., and Jiang, C.: The Impacts of Different PBL Schemes on the Simulation of $\mathrm{PM}_{2.5}$ during Severe Haze Episodes in the Jing-Jin-Ji Region and Its Surroundings in China, Adu. Meteorol., 6295878, https://doi.org/10.1155/2016/6295878, 2016.

Li, Y.: On the Surface Turbulent Fluxes Calculation in Numerical Models, University of Chinese Academy of Sciences, Beijing, 2014.

Li, Y., Gao, Z., Li, D., Wang, L., and Wang, H.: An improved non-iterative surface layer flux scheme for atmospheric sta- ble stratification conditions, Geosci. Model Dev., 7, 515-529, https://doi.org/10.5194/gmd-7-515-2014, 2014.

Li, Y., Gao, Z., Li, D., Chen, F., Yang, Y., and Sun, L.: An Update of Non-iterative Solutions for Surface Fluxes Under Unstable Conditions, Bound.-Lay. Meteorol., 156, 501-511, https://doi.org/10.1007/s10546-015-0032-x, 2015.

Li, Y., Gao, Z., Li, D., Chen, F., Yang, Y., and Sun, L.: Erratum to: An Update of Non-iterative Solutions for Surface Fluxes Under Unstable Conditions, Bound.-Lay. Meteorol., 161, 225-228, 2016.

Li, Z., Guo, J., Ding, A., Liao, H., Liu, J., Sun, Y., Wang, T., Xue, H., Zhang, H., and Zhu, B.: Aerosol and boundary-layer interactions and impact on air quality, Natl. Sci. Rev., 4, 810-833, https://doi.org/10.1093/nsr/nwx117, 2017.

Liu, T., Gong, S., He, J., Yu, M., Wang, Q., Li, H., Liu, W., Zhang, J., Li, L., Wang, X., Li, S., Lu, Y., Du, H., Wang, Y., Zhou, C., Liu, H., and Zhao, Q.: Attributions of meteorological and emission factors to the 2015 winter severe haze pollution episodes in China's Jing-Jin-Ji area, Atmos. Chem. Phys., 17, 2971-2980, https://doi.org/10.5194/acp-17-2971-2017, 2017.

Louis, J. F.: A parametric model of vertical eddy fluxes in the atmosphere. Bound.-Lay. Meteorol., 17, 187-202, https://doi.org/10.1007/BF00117978, 1979.

Louis, J. F., Tiedtke, M., and Geleyn, J. F.: A short history of the operational PBL parameterization at ECMWF, in Workshop on Planetary Boundary Layer Parameterization, November 1981, ECMWF, Reading, UK, 59-79, 1982.

Monin, A. S. and Obukhov, A. M.: Basic laws of turbulent mixing in the surface layer of the atmosphere, Contrib. Geophys. Inst. Acad. Sci., USSR, 24, 163-187, 1954.

Paulson, C. A.: The mathematical representation of wind speed and temperature profiles in the unstable atmospheric surface layer, J. Appl. Meteorol., 9, 857-861, 1970.

Sicart, J. E., Litt, M., Helgason, W., Tahar, V. B., and Chaperon, T.: A study of the atmospheric surface layer and roughness lengths on the high-altitude tropical Zongo glacier, Bolivia, J. Geophys. Res.-Atmos., 119, 3793-3808, https://doi.org/10.1002/2013JD020615, 2014.

Simpson, I. J., Thurtell, G. W., Neumann, H. H., Den Hartog, G., and Edwards, G. C.: The Validity of Similarity Theory in the Roughness Sublayer Above Forests, Bound.-Lay. Meteorol., 87, 69-99, https://doi.org/10.1023/A:1000809902980, 1998.

Stewart, J. B., Kustas, W. P., Humes, K. S., Nichols, W. D., Moran, M. S., and De Bruin, H. A. R.: Sensible heat flux-radiometric surface temperature relationship for eight semiarid areas, J. Appl. Meteorol., 33, 1110-1117, 1994.

Stull, R. B.: An Introduction to Boundary Layer Meteorology, Kluwer Academic Publishers, London, 1988.

Sugawara, H. and Narita, K.: Roughness length for heat over an urban canopy, Theor. Appl. Climatol., 95, 291-299, https://doi.org/10.1007/s00704-008-0007-7, 2009.

Sun, J.: Diurnal Variations of Thermal Roughness Height over a Grassland, Bound.-Lay. Meteorol., 92, 407-427, https://doi.org/10.1023/A:1002071421362, 1999.

Tymvios, F., Charalambous, D., Michaelides, S., and Lelieveld, J.: Intercomparison of boundary layer parameterizations for summer conditions in the eastern Mediterranean island of Cyprus using the WRF-ARW model, Atmos. Res., 208, 45-59, https://doi.org/10.1016/j.atmosres.2017.09.011, 2017. 
Vautard, R., Moran, M. D., Solazzo, E., Gilliam, R. C., Matthias, V., Bianconi, R., Chemel, C., Ferreira, J., Geyer, B., Hansen, A. B., Jericevic, A., Prank, M., Segers, A., Silver, J. D., Werhahn, J., Eolke, R., Rao, S. T., and Galmarini, S.: Evaluation of the meteorological forcing used for the Air Quality Model Evaluation International Initiative (AQMEII) air quality simulations, Atmos. Environ., 53, 15-37, https://doi.org/10.1016/j.atmosenv.2011.10.065, 2012.

Verhoef, A., De Bruin, H. A. R., and Van Den Hurk, B. J. J. M.: Some Practical Notes on the Parameter kB-1 for Sparse Vegetation., J. Appl. Meteorol., 36, 560-572, 1997.

Wang, H., Tan, S. C., Wang, Y., Jiang, C., Shi, G., Zhang, M., and Che, H. Z.: A multisource observation study of the severe prolonged regional haze episode over eastern China in January 2013, Atmos. Environ., 89, 807-815, https://doi.org/10.1016/j.atmosenv.2014.03.004, 2014.

Wang, H., Shi, G. Y., Zhang, X. Y., Gong, S. L., Tan, S. C., Chen, B., Che, H. Z., and Li, T.: Mesoscale modelling study of the interactions between aerosols and PBL meteorology during a haze episode in China Jing-Jin-Ji and its near surrounding region - Part 2: Aerosols' radiative feedback effects, Atmos. Chem. Phys., 15, 3277-3287, https://doi.org/10.5194/acp15-3277-2015, 2015a.

Wang, H., Xue, M., Zhang, X. Y., Liu, H. L., Zhou, C. H., Tan, S. C., Che, H. Z., Chen, B., and Li, T.: Mesoscale modeling study of the interactions between aerosols and PBL meteorology during a haze episode in Jing-Jin-Ji (China) and its nearby surrounding region - Part 1: Aerosol distributions and meteorological features, Atmos. Chem. Phys., 15, 3257-3275, https://doi.org/10.5194/acp-15-3257-2015, 2015b.

Wang, S., Wang, Q., and Doyle, J.: Some improvements to Louis surface flux parameterization. Paper presented at 15th symposium on boundary layers and turbulence, American Meteorological Society, Wageningen, Netherlands, 15-19, 2002.

Webb, E. K.: Profile relationships: The log-linear range, and extension to strong stability, Q. J. Roy. Meteorol. Soc., 96, 67-90, 1970.

Webb, E. K., Pearman, G. I., and Leuning, R.: Correction of flux measurements for density effects due to heat and water vapour transfer, Q. J. Roy. Meteorol. Soc., 106, 85-100, 1980.
Wouters, H., De Ridder, K., and van Lipzig, N. P. M.: Comprehensive Parametrization of Surface-Layer Transfer Coefficients for Use in Atmospheric Numerical Models, Bound.-Lay. Meteorol, 145, 539-550, https://doi.org/10.1007/s10546-012-9744-3, 2012.

Xie, B., Fung, J. C. H., Chan, A., and Lau, A.: Evaluation of nonlocal and local planetary boundary layer schemes in the WRF model, J. Geophys. Res.-Atmos., 117, 48-50, https://doi.org/10.1029/2011JD017080, 2012.

Yang, K., Tamai, N., and Koike, T.: Analytical Solution of Surface Layer Similarity Equations, J. Appl. Meteorol., 40, 1647-1653, 2001.

Yang, K., Koike, T., and Yang, D.: Surface Flux Parameterization in the Tibetan Plateau, Bound.-Lay. Meteorol., 106, 245-262, https://doi.org/10.1023/A:1021152407334, 2003.

Yang, K., Koike, T., Ishikawa, H., Kim, J., Li, X., Liu, H., Liu, S., Ma, Y., and Wang, J.: Turbulent Flux Transfer over Bare-Soil Surfaces: Characteristics and Parameterization, J. Appl. Meteorol. Clim., 47, 276-290, https://doi.org/10.1175/2007jamc1547.1, 2008.

Yang, Y., Liu, X., Qu, Y., Wang, J., An, J., Zhang, Y., and Zhang, F.: Formation mechanism of continuous extreme haze episodes in the megacity Beijing, China, in January 2013, Atmos. Res., 155, 192-203, https://doi.org/10.1016/j.atmosres.2014.11.023, 2015.

Zhang, B., Wang, Y., and Hao, J.: Simulating aerosol-radiationcloud feedbacks on meteorology and air quality over eastern China under severe haze conditionsin winter, Atmos. Chem. Phys., 15, 2387-2404, https://doi.org/10.5194/acp-152387-2015, 2015.

Zhang, D. and Anthes, R. A.: A high-resolution model of the planetary boundary layer-Sensitivity tests and comparisons with SESAME-79 data, J. Appl. Meteorol., 21, 1594-1609, 1982.

Zhang, R., Li, Q., and Zhang, R.: Meteorological conditions for the persistent severe fog and haze event over eastern China in January 2013, Sci. China Earth Sci., 57, 26-35, https://doi.org/10.1007/s11430-013-4774-3, 2014.

Zhong, J., Zhang, X., Dong, Y., Wang, Y., Liu, C., Wang, J., Zhang, Y., and Che, H.: Feedback effects of boundary-layer meteorological factors on cumulative explosive growth of $\mathrm{PM}_{2.5}$ during winter heavy pollution episodes in Beijing from 2013 to 2016, Atmos. Chem. Phys., 18, 247-258, https://doi.org/10.5194/acp18-247-2018, 2018. 